\title{
Rainer Schmitt, Ulrich Lanz (eds): Diagnostic Imaging of the Hand
}

\section{7, 608 pp; num. ill. Hardcover, EUR(D) 179.95 CHF 299.00, Georg Thieme Verlag, Stuttgart, New York, ISBN 13:978-313140581-4}

\author{
Pierre Kehr • Alain Graftiaux
}

Received: 26 October 2008 / Accepted: 27 October 2008 / Published online: 14 November 2008

(C) Springer-Verlag 2008

This translated book of the first German version, takes into account the projections of the last decade in the diagnosis in particular by scanner, MRI may so echography. The advantage of this book lies in the parallelization of the radiological signs, the physio-anatomy, and sometimes of the results of the arthroscopies in particular to the wrist. The correlation with clinical classifications and the therapeutic possibilities makes it possible "to validate" the various examinations presented pathology by pathology. On 600 pages one makes the turn of different possibilities and pathologies from the wrist and the hand.

This book will interest all the surgeons that the surgery of the hand and the wrist impassion and will help them to choose the best examinations to have the most precise possible diagnosis.

Conflict of interest statement No funds were received in support of this study. 